\title{
CARBONIC ANHYDRASE INHIBITORS. Part 40.1 GERMYL AMINES AND GERMANOLS INHIBIT CARBONIC ANHYDRASE ISOZYME II BUT NOT ISOZYME I
}

\author{
Monique Rivière-Baudet ${ }^{1}$ and Claudiu T. Supuran ${ }^{2 \star}$ \\ 1 Universite Paul Sabatier, Laboratoire d'Heterochimie Fondamentale et Appliquee, \\ URA 477 du CNRS, 118, Route de Narbonne, F-31062 Toulouse Cedex, France. \\ 2 Università degli Studi, Laboratorio di Chimica Inorganica e Bioinorganica, Via Gino Capponi 7, \\ I-50121, Firenze, Italia
}

\begin{abstract}
The interaction of carbonic anhydrase (CA) isozymes I and II with Ge(IV) derivatives was investigated kinetically and spectrophotometrically, utilizing the native and $\mathrm{Co}$ (II)-substituted enzymes. Trimesitylgermyl amine and trimesitylgermanol act as uncompetitive inhibitors for isozyme CA II (with $\mathrm{CO}_{2}$ and 4-nitrophenyl acetate as substrates) but they do not inhibit at all isozyme CA I. The related derivatives possessing carbon instead of germanium, i.e., triphenylcarbinol and triphenylmethylamine do not inhibit any of the two investigated CA isozyme. A mechanism explaining this behaviour is proposed.
\end{abstract}

\section{Introduction}

In addition to aromatic and heterocyclic sulfonamides with the general formula $\mathrm{R}-\mathrm{SO}_{2} \mathrm{NH}_{2}$ - the classical inhibitors of the zinc enzyme carbonic anhydrase (CA, EC 4.2.1.1 $)^{2,3}$ - in the last period this type of biological activity has been detected for other classes of compounds. Screening of a large series of substances for putative CA inhibition is critical for at least two reasons: (i) the large number of CA isozymes known (at least nine were described in vertebrates) ${ }^{4}$ coupled with a scarcity of data regarding the physiological role for many of them ${ }^{3-5}$; (ii) the possible clinical applications of these inhibitors, as some sulfonamides possessing CA inhibitory properties are widely employed pharmaceuticals in the treatment or prevention of many diseases, such as glaucoma, ${ }^{2.3 .5}$ gastro-duodenal ulcers, ${ }^{6}$ mountain sickness, ${ }^{7}$ or minor forms of epilepsia ${ }^{8}$ among others.

Thus, Lindskog's group reported phenol as the unique $\mathrm{CO}_{2}$ competitive inhibitor of isozyme CA II, ${ }^{9}$ and the X-ray crystallographic structure of this adduct was reported recently by Nair et al. ${ }^{10}$ Thiophenols and aliphatic or heterocyclic mercaptans with the formula R-SH have also been reported to act as CA II inhibitors, ${ }^{11-13}$ whereas Bertini's group ${ }^{14}$ reported aniline to inhibit native- and Co(II)-substituted isozyme II. More recently we also proved this type of biological activity for some $P(V)^{1,15}$ and $A s(V)$ derivatives. ${ }^{16}$

As seen from the above data all compounds acting as effective inhibitors for some CA isozymes possess a coordinating functional group (such as $\mathrm{SO}_{2} \mathrm{NH}_{2}, \mathrm{SH}, \mathrm{OH}, \mathrm{NH}_{2}$ ) generally attached to a bulky structural element (such as an aromatic/heterocyclic ring, possibly substituted with several side chains). Both of these elements are extremely important for inhibition, as the first moiety generally directly interacts with the metal center or the solvent molecule bound to the metal ion, ${ }^{2,3,14.17-19}$ whereas the second one assures stability to the enzyme-inhibitor adduct by means of cooperative interactions with amino acid side chains lining the active site. This was well illustrated in the case of the sulfonamide inhibitors, by the report of the X-ray crystallographic structures of several adducts of isozymes CA I - III with such inhibitors, by Liljas' group. ${ }^{20,2}$

The recent discovery of CA inhibitory properties (towards CA II) with (thio)phosphorylic $(\mathrm{P}(\mathrm{V}))^{1.15}$ and hydroxyarsonic $(\mathrm{As}(\mathrm{V}))^{16}$ derivatives, prompted us to investigate other organometallic compounds possessing the above-mentioned structural elements in their molecule for their interaction with the major $\mathrm{CA}$ isozymes, i.e., CA I and CA II. Here we report that derivatives $1-4$ of the type $\mathrm{R}_{3} \mathrm{E}-\mathrm{X}$, where $\mathrm{X}=\mathrm{NH}_{2}$ or $\mathrm{OH}$ act as $\mathrm{CA}$ II inhibitors when $\mathrm{E}=\mathrm{Ge}$, but not when $\mathrm{E}$ is carbon ( $\mathrm{R}$ is a bulky aromatic moiety, phenyl or 
mesityl). What is most interesting is the fact that none of the above compounds inhibited isozyme CA I. A mechanism is also proposed to explain this strange behaviour.
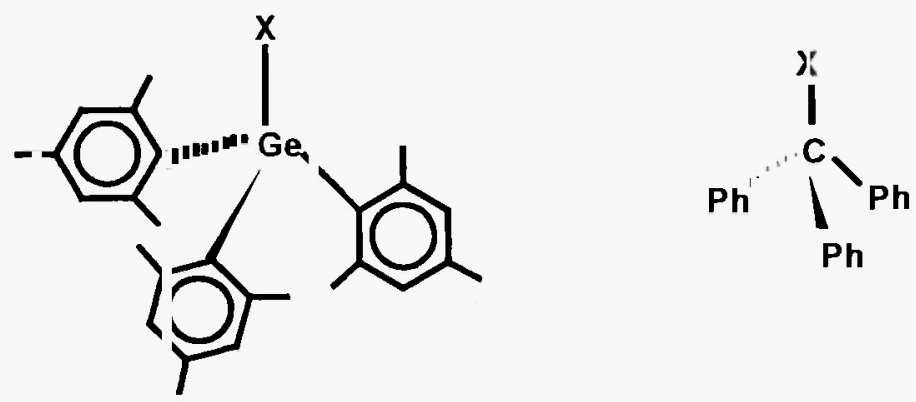

$$
\begin{aligned}
& \text { 1: } \mathrm{X}=\mathrm{OH} \\
& \text { 2: } \mathrm{X}=\mathrm{NH}_{2}
\end{aligned}
$$$$
\text { 3: } \mathrm{X}=\mathrm{OH}
$$$$
\text { 4: } \mathrm{X}=\mathrm{NH}_{2}
$$

\section{Materials and Methods}

The Ge(IV) derivatives 1 and 2 were prepared as described in the literature, ${ }^{223}$ whereas triphenylcarbinol 3 and triphenylmethylamine + were from Aldrich. Buffers, 4-nitrophenyl acetate somatostatin and inorganic reagents from Sigma were used without additional purification. Human CA I and CA II cDNAs were expressed in Ion Escherichia coli strain SG20043 from the plasmids described by Forsman et al. ${ }^{24}$ (the two plasmids were a gift from Prof. Sven Lindskog, Umea University. Sweden). Cell growth conditions were those described by Lindskog's group, ${ }^{-5}$ and enzymes were purified by affinity chromatography according to the method of Khalifah et al ${ }^{26}$ Enzyme concentrations were determined spectrophotometrically at $280 \mathrm{~nm}$. utilizing a molar absorptivity of $49 \mathrm{mM}^{-1} . \mathrm{cm}^{-1}$ for CA I and $54 \mathrm{mM}^{-1} . \mathrm{cm}^{-1}$ for CA II. respectively, based on $\mathrm{M}_{\mathrm{I}}=28.85 \mathrm{kDa}$ for CA I. and $29.3 \mathrm{kDa}$ for CA II. respectively. ${ }^{27 .} .8$ Apoenzyines were prepared by dialysing the zinc enzymes against $50 \mathrm{nM}$ pyridine-2.6-dicarboxylic acid (Sigma) in $0.2 \mathrm{M}$ phosphate buffer at $4^{\circ} \mathrm{C}$ for 2 hours. ${ }^{29}$ The chelating agent was removed by dialysis against $20 \mathrm{mM}$ Tris- $\mathrm{H}_{2} \mathrm{SO}_{4}(\mathrm{pH} 7.5)$ and then 1.1 equivalents of $\mathrm{CoSO}_{4}$ were added to the apoenzymes in order to obtain Co(II)CAs.

Electronic spectra were recorded with a Cary 3 spectrophotometer interfaced with an IBM PC. Inhibitors were assayed for inhibition of $\mathrm{CO}_{2}$ hydration by Maren's micromethod ${ }^{30}$ at $0^{\circ} \mathrm{C}$. in the conditions of the E-I (enzyme-inhibitor) technique. ${ }^{230}$ Stock solution of inhibitors $(10 \mathrm{mM})$ were prepared in DMSO (from Merck) and dilutions up to $10^{-6} \mathrm{M}$ were done with distilled-deionized water. Hepes buffer (pH 7.4) was used, and the enzyme and inhibitor solutions were preincubated for $15 \mathrm{~min}$. at room temperature, in order to allow the formation of the E-I adduct. The concentration of CA I used in these experiments was 10 $\mathrm{nM}$, whereas that of CA II was of $2 \mathrm{nM}$. IC 50 values represent the molarity of inhibitor producing a $50 \%$ decrease of enzyme specific activity for the investigated reaction. Inhibition of the esterase activity against 4-nitrophenylacetate as substrate was assayed by the method of Pocker and Stone. ${ }^{31}$

Kinetic measurements for $\mathrm{CO}_{2}$ hydration were done by a stopped flow method spectrophotometrically. ${ }^{32}$ Initial rates of carbon dioxide hydration were measured on a Hi-Tech (London, England) instrument at $25^{\circ} \mathrm{C}$ using the following buffer/indicator system : Hepes $(5 \mathrm{mM} \mathrm{pH} 7.5) / 4-$ nitrophenol (3\%). Measurements were done at $400 \mathrm{~nm}$. The photomultiplier signal was fed into a Multi Mixing Stopped Flow SHU apparatus (Hi-Tech) interfaced with an IBM-compatible PC, possessing a DAS50 Omega interface. Data acquisition was done with a program written by one of us. Initial $\mathrm{CO}_{2}$ concentrations were determined with a kit from Gilford Systems (Oberlin, OH, USA) by using a phosphoenol pyruvate carboxylase - malate dehydrogenase method, ${ }^{33}$ spectrophotometrically, at $340 \mathrm{~nm}$, with a Cary 3 instrument. Rate data were fitted to Michaelis - Menten's kinetic equation by using the EadieHofstee approach, with a program written by us.

\section{Results and Discussion}

Inhibition data against CA I and II with derivatives 1-4, for the hydrase $\left(\mathrm{CO}_{2}\right.$ as substrate) and esterase (4-nitrophenylacetate as substrate) activities are shown in Table I. 
Table I: Inhibition data of compounds 1-4 against human CA isozymes I and II, for the hydrase activity (A) and esterase activity (B) of these enzymes.

\begin{tabular}{|c|c|c|c|c|}
\hline \multirow[t]{3}{*}{ Inhibitor } & \multicolumn{4}{|c|}{$\mathrm{IC}_{50}(\mu \mathrm{M})^{\mathrm{a}}$} \\
\hline & \multicolumn{2}{|c|}{ CA I } & \multicolumn{2}{|c|}{ CA II } \\
\hline & A & B & A & B \\
\hline 1 & $>1000$ & $>1000$ & 320 & 85 \\
\hline 2 & $>1000$ & $>1000$ & 240 & 72 \\
\hline 3 & $>2000$ & $>1000$ & 1800 & $>1000$ \\
\hline 4 & $>2000$ & $>1000$ & $>2000$ & $>1000$ \\
\hline
\end{tabular}

${ }^{a}$ Mean of duplicate experiments.

From data of Table I one can see that the Ge(IV) derivatives 1 and 2 only inhibit isozyme CA II, whereas they are ineffective against isozyme I. The structurally related carbon derivatives 3 and 4 on the other hand do not inhibit anyone of the two CA isozymes. It is noteworthy that the two Ge(IV) derivatives possess inhibitory properties against CA II comparable to those of the recently described inhibitors sulfamic acid $\mathrm{H}_{2} \mathrm{NSO}_{3} \mathrm{H}$ or sulfamide $\mathrm{H}_{2} \mathrm{NSO}_{2} \mathrm{NH}_{2}$ for both reactions catalyzed by this isozyme. ${ }^{34}$ Thus, they are stronger inhibitors for the estarsic activity than the hydrase one, with the germyl amine a slightly better inhibitor than the germanol.

The large majority of $\mathrm{CA}$ inhibitors described up to now, such as the metal complexing anions $\left(\mathrm{CN}^{-}, \mathrm{CNO}^{-} \mathrm{SCN}^{-}\right.$. $\mathrm{HS}$. etc), ${ }^{35}$ the sulfonamides, ${ }^{3.36}$ the mercaptans, ${ }^{11}$ or the $\mathrm{P}(\mathrm{V})$ and $\mathrm{As}(\mathrm{V})$ derivatives ${ }^{1.1516}$ act as non-competitive inhibitors with the physiological substrate of these enymes, $\mathrm{CO}_{2}$. This is due to the fact that all these inhibitors bind to the metal ion within the enzyme active site. substituting the metal-bound solvent molecule or ion (depending on $\mathrm{pH}$ ) or adding to the coordination sphere of the metal. whereas $\mathrm{CO}_{2}$ binds ina hydrophobic pocket ${ }^{37}$ in the neighborhood of the metal center. but is never directly coordinated to this. ${ }^{7 i .18}$ The notable exceptions are constituted by two $\mathrm{CO}_{2}$-competitive inhibitors described so far: imidazole for CA I. ${ }^{32}$ and phenol for CA II. ${ }^{9}$ X-ray crystallographic data shown these inhibitors to bind in the neighborhood of the metal center. without displacing the $\mathrm{Zn}$ (II)-bound solvent molecule/ion (a water or a hỵdroxide ion, respectively. depending on $\mathrm{pH}$ ) but forming hỵdrogen bonds with it. ${ }^{10.38}$ Finally, the only uncompetitive inhibitors with the substrate $\mathrm{CO}_{2}$ described so far are the tetradecapeptide somatostatin and its synthetic analogue octreotide. ${ }^{39}$ In this case it was proposed ${ }^{39}$ that non-covalent. catalytically unproductive ternary complexes are formed between the enzy me, its substrate and the inhibitors, but a precise binding mode could not be established, apart of the fact that the two uncompetitive inhibitors had an identical tetrapeptide central sequence that seemed to be critical for binding.

Thus, compounds 1 and 2 were also investigated kinetically in order to determine the type of interaction with the unique isozyme they inhibit, CA II (Table II).

Table II: Kinetic parameters for the interaction of CA II with compounds 1 and 2.

\begin{tabular}{|c|c|c|}
\hline System & $\mathrm{K}_{\mathrm{m}}^{\mathrm{a}}(\mathrm{mM})$ & $\mathrm{V}_{\max }{ }^{\mathrm{a}}\left(\mathrm{mM}^{-1} \cdot \mathrm{s}^{-1}\right)$ \\
\hline $\mathrm{CA} \mathrm{II}^{\mathrm{b}}$ & $9.1 \pm 0.3$ & $1.05 \pm 0.20$ \\
\hline $\mathrm{CA} \mathrm{II}+\mathbf{1}^{\mathrm{c}}$ & $7.8+0.4$ & $0.92 \pm 0.15$ \\
\hline $\mathrm{CA} \mathrm{II}+2^{\mathrm{c}}$ & $7.4 \pm 0.2$ & $0.84 \pm 0.21$ \\
\hline CA ll+ somatostatin & $7.85+0.10$ & $0.91 \pm 0.0 .15$ \\
\hline
\end{tabular}

${ }^{a}$ Mean \pm standard deviation (from 3 determinations)

${ }^{b}$ In all experiments [CA II] $=0.8 \mathrm{nM}, \mathrm{pH} 7.5$ (5 mM Hepes).

${ }^{c}$ [inhibitor $]=150 \mu \mathrm{M} ;{ }^{d}$ From ref. ${ }^{39}$. 
Table III: Electronic spectral data (in the range 400-750 $\mathrm{nm}$ ) for adducts of Co(II)CA II with inhibitors 1, 2 and somatostatin. Enzyme concentrations were in the range $0.5-1.2 \mathrm{mM}$ and $\mathrm{pH}$ values specified in each case. Inhibitor concentrations were in the range $10-18 \mathrm{mM}$.

\begin{tabular}{lll}
\hline Adduct & pH & Band position, $\mathrm{nm}\left(\right.$ molar absorptivity $\left.\left[\mathrm{M}^{-1} \mathrm{x} \mathrm{cm}^{-1}\right]\right)$ \\
\hline pure enzyme & 5.0 & $520(180) ; 550(250) ; 616.5(135) ; 640(100)$ \\
pure enzyme & 8.0 & $520(280) ; 550(380) ; 616.5(280) ; 640(260)$ \\
1 & 6.0 & $520(178) ; 550(250) ; 616.5(134) ; 640(101)$ \\
2 & 5.0 & $520(179) ; 550(250) ; 616.5(134) ; 640(100)$ \\
somatostatin & 6.0 & $519(177) ; 550(250) ; 616.5(134) ; 640(101)$
\end{tabular}

Electronic spectral data for the adducts of Co(II)-CA II with inhibitors 1. 2 and somatostatin (Table III) clearly show that these compounds do not interact with the metal center, as the spectra of the adducts are very similar to those of the pure enzyme. It is also well-known that the Co(II) ion in CoCA is a good spectroscopic probe for the environment of the active site ${ }^{40}$ and very characteristic spectra were described for adducts with sulfonamide or anion inhibitors. ${ }^{41.42}$

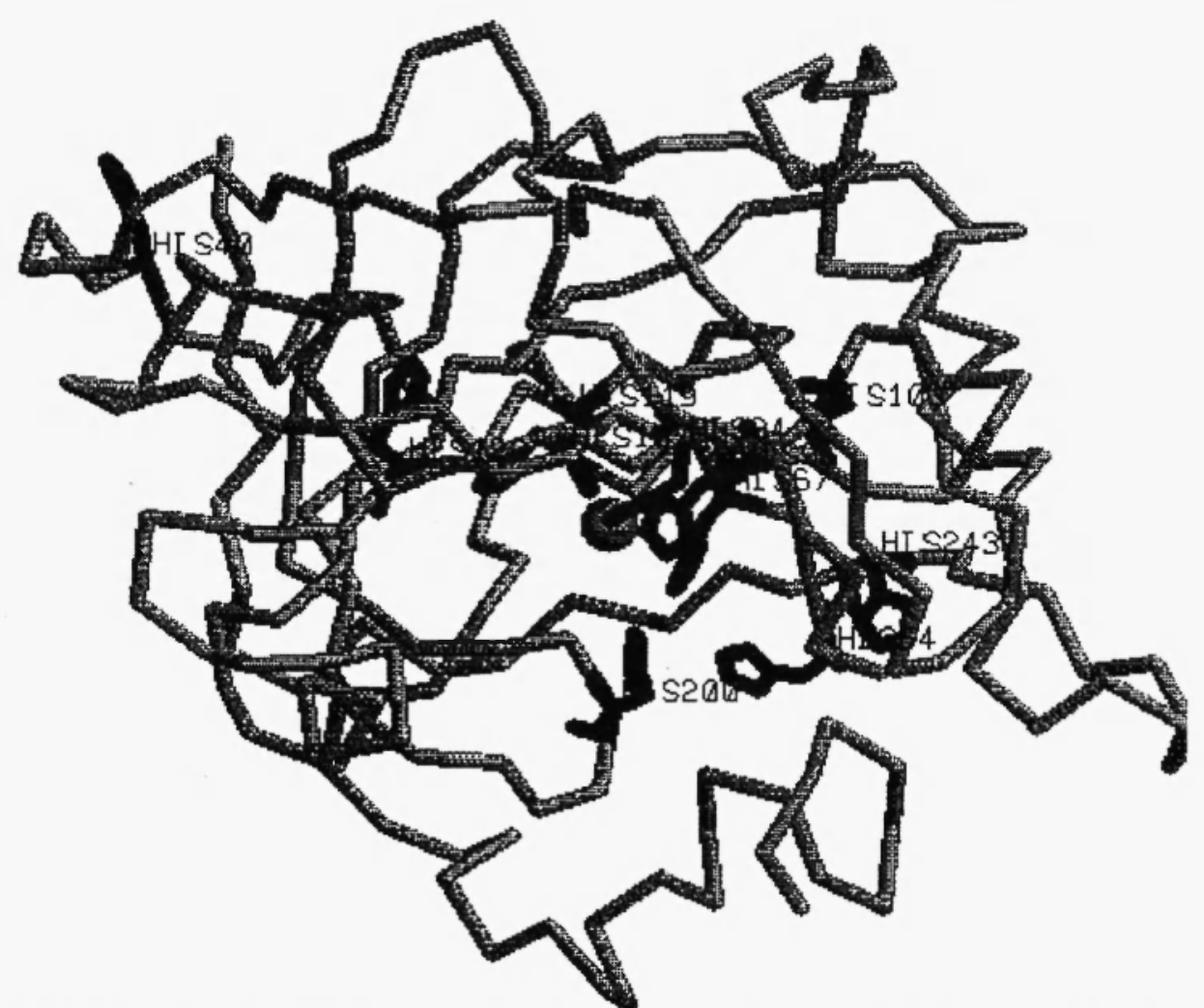

Fig. 1: CA I with the $\mathrm{Zn}$ (II) ion and the histidine residues evidenced (from ref. ${ }^{43}$ ). The X-ray crystallographic coordinates of the protein were taken from Brokhaven Protein Data Base via Internet, and the program RasMol for Windows (version 2.6) was used to generate the above figure as well as for measuring distances, with a Texas Instruments $4000 \mathrm{M}$ personal computer.

The kinetic and spectroscopic data presented throughout the paper as well as the net difference between the bahaviour of the two CA isozymes in interacting with inhibitors 1 and 2 prompted us to look upon the explanation of our discovery in features that are characteristic only to isozyme II. Thus, CA II is 
one of the most cffective catalysts known ${ }^{37}$ with $\mathrm{k}_{\mathrm{cat}} / \mathrm{K}_{\mathrm{m}}$ of $1.4 .10^{8} \mathrm{M}^{-1} \cdot \mathrm{s}^{-1}$, whereas CA I is somehow less cffective, with $\mathrm{k}_{\mathrm{cat}} / \mathrm{K}_{\mathrm{ml}}$ of $5.10^{7} \mathrm{M}^{-1} \cdot \mathrm{s}^{-1} .{ }^{3.37}$ Although the zinc ligands and the architecture of the active site is very similar for these two isozymes possessing a high degree of homology, the kinetic differences as well as their different susceptibilitics for scveral classes of inhibitors are presently far from being understood. ${ }^{3}$

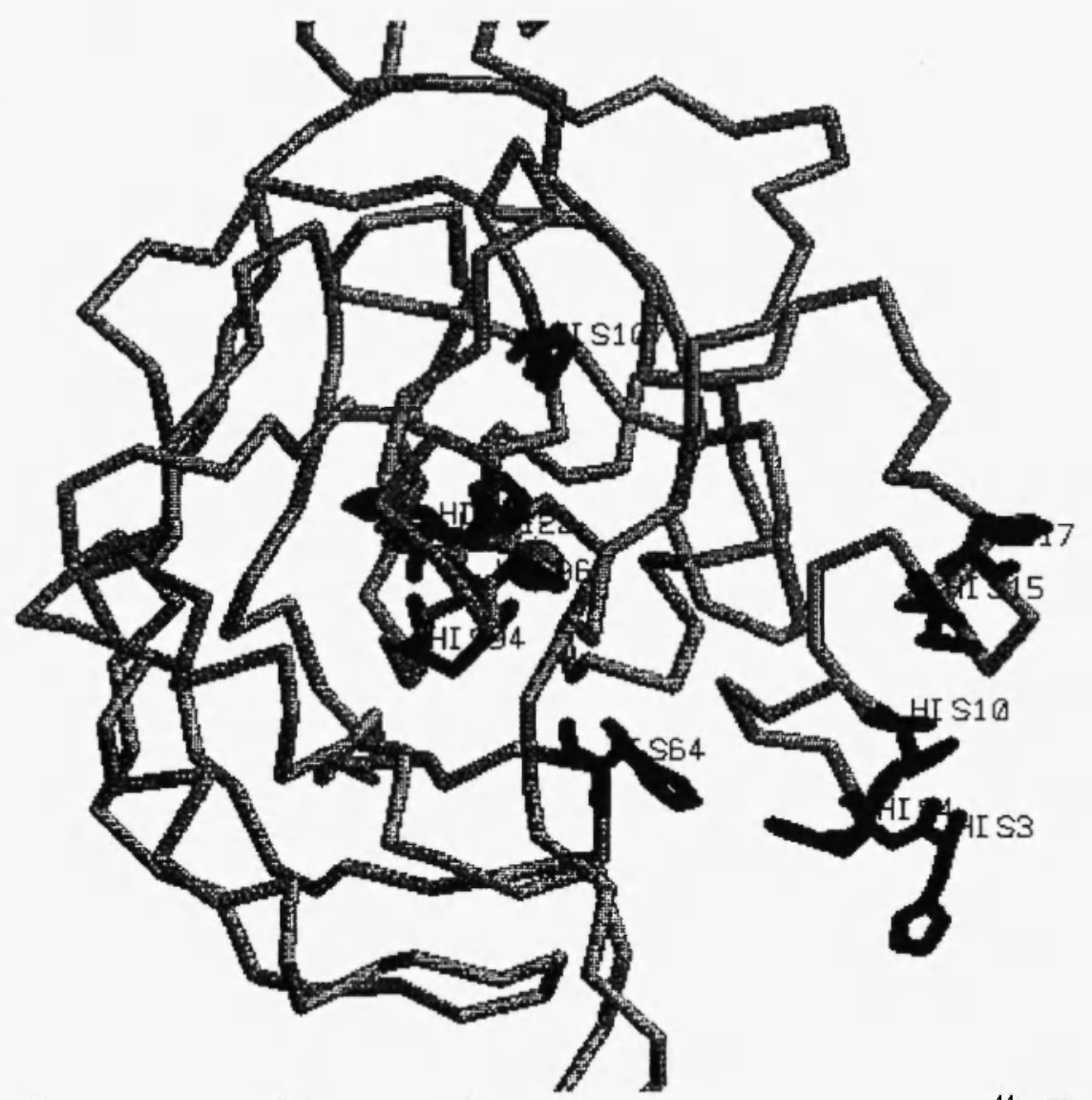

Fig. 2 Isozyme CA Il with the $\mathrm{Zn}(\mathrm{II})$ ion and histidine residues evidenced (from ref. ${ }^{44}$ ). The figure was generated as described above for isozyme CA I.

As seen from data of Figures 1 and 2, although the general shape of the molecule is quite similar for these two CA isozymes, ${ }^{43.44}$ important differences consist in the number and location of histidine residues within the active site. Except for the three zinc ligands (His 94, His 96 and His 119) and the buried residue His 107 (which forms several hydrogen bonds involving among others Glu 117 and the zinc ligand His 119$)^{45}$ with a role in stabilizing the conformation at the bottom of the active site, ${ }^{45,46}$ which are identical for both CA I and CA II, the active site of CA I is richer in such residues. Thus, other 4 histidines are present, i.e., His 64, His 67, His 200 and His 243 (Fig. 1). In the case of CA II, only one such residue is present, His 64 , but which plays a critical role in the catalytic cycle, being the proton shuttle residue that allows the very high turnover of this isozyme. ${ }^{47}$ In contrast with the corresponding residue in CA I, His 64 in CA II is very exposed to the solvent being able to transfer protons from the active site to buffer molecules in solution, ${ }^{47}$ or as proposed by us, to the neighbouring histidine cluster consisting of residues His 3 , His 4 , His 10, His 15 and His 17, situated just at the entrance of the active site cavity (Fig. 2). Such a cluster of histidines (or other polar residues) is absent in isozyme I. It is just this region at the entrance of the active site cavity that we propose as the binding site of the bulky compounds 1 and 2 . The presence of the amino or hydroxy moiety polarized by the voluminous Ge(IV) atom would presumably favour interaction with this polar region at the entrance of the active site, and in the same time it would hinder the access of substrate molecules to the catalytically vital $\mathrm{Zn}$ (II) ion. Such a model explains both the kinetic as well as 
spectroscopic behaviour of inhibitors 1 and 2 and would also explain why in the case of the carbon derivatives 3, 4 interaction does not occur (presumably the polarization induced by the carbon atom is not enough as compared to that of $\mathrm{Ge}$ for activating the corresponding compound to interact with the histidines at the entrance of CA II active site, or the corresponding carbon derivatives are not bulky enough). It should be noted that up to now only $\mathrm{Cu}$ (II) and $\mathrm{Hg}$ (II) ions were reported to bind to His 64 . blocking in this way the proton transferring capacities of the enzyme and the whole catalytic cycle. ${ }^{48}$ It is to note that the two histidine residues of isozyme I which are somehow exposed (evidenced in Fig. 1), more precisely His 64 and His 200 cannot act as efficient proton shuttles ${ }^{37.47}$ and probably would not interact easily with the Ge(IV) derivatives, as they are too burried (as compared to the His-64, His-3, His 4 triplet of isozyme II, which somehow protrudes out of the active site entrance, as seen from Fig. 2). This explains why only CA II was inhibited with these derivatives.

In conclusion, in the present paper we present the first evidence of non-peptidc CA II inhibitors acting uncompetitively with the substrate $\mathrm{CO}_{2}$ and explain our results in terms of specific interactions with histidine residues at the entrance of the active site cavity. This type of approach could lead to the development of more selective isozyme-specific inhibitors.

\section{Acknowledgements.}

Special thanks are addressed to Prof. Sven Lindskog (Umea University, Sweden) for the gift of plasmids used to obtain CA I and CA II. This research was financed in part by the EU grant ERBCIPDCT 940051.

\section{References}

1. Preceding part of this series: A. Scozzafava. F. Briganti, C.T.Supuran. I. Fenesan. R. Popescu. V. Muresan and S. Farcas. Main Group Met. Chem.. in press.

2. T.H.Maren, Pharmacol.Rev.. 1967, 47. 595-782.

3. C.T.Supuran. "Carbonic anhydrase inhibitors", in "Carbonic Anhydrase and Modulation of Physiologic and Pathologic Processes in the Organism". I.Puscas Ed.. Helicon, Timisoara 1994. pp. 29-111.

4. R.E.Tashian. $4^{\mathrm{th}}$ Carbonic Anhydrase International Conference. Oxford, UK. July 1995. and Adv. Genet., 1992. 30. 321-356

5. T.H.Maren. J. Glaucoma. 1995. 4. 49-62.

6. I.Puscas and C.T.Supuran. "Farmacologia clinica da ulcera peptica" in "Aparelho Digestivo". J.Coelho Ed.. MEDSI, Rio de Janeiro. 1996, pp. 1704-1734.

7. E.B.Larson, R.C.Roach, R.B.Schoene and T.F.Hornbein. J.Am.Med.Ass., 1982. 248. 328-332.

8. D.M.Woodbury. "Carbonic anhydrase inhibitors" in "Antiepileptic Drugs: Mechanism of Action". G.H.Glaser. J.K.Penry and D.M.Woodbury Eds.. Raven, New York, 1980, pp. 617-633.

9. 1.Simonsson, B.H.Jonsson and S.Lindskog. Biochem.Biophys.Res.Commun., 1982, 108, 1406-1412.

10. S.K.Nair, P.A.Ludwig and D.W.Christianson. J.Am.Chem.Soc., 1994, 116, 3659-3660.

11 S.Schwimmer, Enzymologia 1969, 37, 163-173.

12. C.T.Supuran, M.D.Banciu, G.Botez and A.T.Balaban, Rev.Roum.Chim., 1992, 37, 1375-1383.

13. C.T.Supuran, I.Saramet and M.D.Banciu, Rev.Roum.Chim., 1995, 40, 1227-1232.

14. 1.Bertini, G.Canti, C.Luchinat and A.Scozzafava, J.Am.Chem.Soc., 1978, 100, 4873-4877.

15. C.T.Supuran, V.Muresan, R.Popescu and I.Fenesan, Main Group Met. Chem., 1995, 18, 629-632.

16. C.T.Supuran, S.V.Serves and P.V.Ioannou, J.Inorg.Biochem., 1996, 62, 207-213.

17 S.Lindskog and A.Liljas, Curr.Opin.Struct.Biol., 1993, 3, 915-920.

18. S.Lindskog and A.Liljas, Roum.Chem.Quart.Rev., 1994, 2, 243-258.

19. A. Liljas, K.Hakansson, B.H.Jonsson and Y.Xue, Eur.J.Biochem., 1994, 219. 1-10.

20. J.Vidgren, A.Svensson and A.Liljas, Int.J.Biol.Macromol., 1993, 15, 97-100.

21. K.Hakansson and A.Liljas, FEBS Lett., 1994, 350, 319-322.

22.a) M.Rivière-Baudet, A.Morere, J.F.Britten and M.Onyszchuk, J.Organomet.Chem., 1992, 423, C5-C8;

b) M.Rivière-Baudet, Main Group Met. Chem., 1995, 18, 353-385. 
23. P.Riviere and M.Riviere-Baudet, Organomet.Synth., 1988, 4, 542.

24. C.Forsman, G.Behravan, A.Osterman and B.H.Jonsson, Acta Chem. Scand., 1988, B42, 314-318.

25. G.Behravan, P.Jonasson, B.H.Jonsson and S.Lindskog, Eur.J.Biochem., 1991, 198, 589-592.

26. R.G.Khalifah, D.J.Strader, S.H.Bryant and S.M.Gibson, Biochemistry, 1977, 16, 2241-2247.

27. P.O.Nyman and S.Lindskog, Biochim.Biophys.Acta, 1964, 85, 141-151.

28. L.E.Henderson, D.Henriksson and P.O.Nyman, J.Biol.Chem., 1976, 251, 5457-5463.

29. J.B.Hunt, M.J.Rhee and C.B.Storm, Anal.Biochem., 1977, 79, 614-617.

30. T.H.Maren, J.Pharmacol.Exp.Ther., 1960, 130, 26-30.

31. Y.Pocker and J.T.Stone, Biochemistry, 1967, 6, 668-679.

32. R.G.Khalifah, J.Biol.Chem., 1971, 246, 2561-2573.

33. R.L.Forrester, L.J.Wataji, D.A.Silverman and K.J.Pierre, Clin.Chem., 1976, 22, 243-247.

34. F.Briganti, R.Pierattelli, A.Scozzafava and C.T.Supuran, Eur.J.Med.Chem., submitted.

35. S.Lindskog, Advan.Inorg.Biochem., 1982, 4, 115-146.

36. J.E.Coleman, Ann.Rev.Pharmacol., 1975, 15, 221-243.

37. D.N.Silverman and S.Lindskog, Acc.Chem.Res., 1988, 21, 30-36.

38. K.K.Kannan, M.Petef, K.Fridborg, H.Cid-Dresdner and S.Lovgren, FEBS Lett., 1977, 73, 115-119.

39. I.Puscas, C.T.Supuran, M.Coltau, F.Chis and I.C.Puscas, Rev.Roum.Biochim., 1994, 31, 171-176.

40. I.Bertini, C.Luchinat and A.Scozzafava, Struct.Bonding, 1982, 48, 45-82.

41. I.Bertini and C.Luchinat, Acc.Chem.Res., 1983, 16, 272-282.

42. I.Bertini, C.Luchinat, R.Pierattelli and A.V.Vila, Eur.J.Biochem., 1992, 208, 607-611.

43. V.Kumar, P. Sathyamurthy and K.K.Kannan, Acta Crystalogr.A, 1987, 43, 21-29.

44. K.Hakansson, M.Carlsson, L.A.Svensson and A.Liljas, J.Mol.Biol., 1992, 227, 1192-1196.

45. C.Tu, J.M.Couton, G.Van Heeke, N.G.J.Richards and D.N.Silverman, J.Biol.Chem., 1993, 268, 47754779.

46. P.J.Venta, R.J.Welty, T.M.Johnson, W.S.Sly and R.E.Tashian, Am.J.Human.Genet., 1991, 49, 10821090.

47. C.Tu, D.N.Silverman, C.Forsman, B.H.Jonsson and S.Lindskog, Biochemistry, 1989, 28, 7913-7918.

48. C.Tu, G.C.Wynns and D.N.Silverman, J.Biol.Chem., 1981, 256, 9466-9470.

\section{Received: June 3, 1996 - Accepted: June 25, 1996 - Received in revised camera-ready format: July 3, 1996}


